\title{
Cotas raciais para concurso de ingresso na magistratura (CNJ)
}

Conselho Nacional de Justiça (CNJ)

EMENTA: PROCESSO COMISSÃO. COMISSÃO PERMANENTE DE EFICIÊNCIA OPERACIONAL E GESTÃO DE PESSOAS. POLÍTICAS PÚBLICAS. CENSO DO PODER JUDICIÁRIO. COTAS. CONCURSO PÚBLICO. AÇÕES AFIRMATIVAS. RESOLUÇÃO.

\section{Acórdão}

Após o voto do Conselheiro vistor Fabiano Silveira, o Conselho, por unanimidade, aprovou a resolução nos termos propostos pelo Relator. Votou o Presidente. Presidiu o julgamento o Conselheiro Ricardo Lewandowski. Plenário, 9 de junho de 2015. Presentes à sessão os Excelentíssimos Senhores Conselheiros Ricardo Lewandowski, Nancy Andrighi, Ana Maria Duarte Amarante Brito, Flavio Sirangelo, Deborah Ciocci, Saulo Casali Bahia, Rubens Curado Silveira, Luiza Cristina Frischeisen, Gilberto Martins, Paulo Teixeira, Gisela Gondin Ramos, Emmanoel Campelo e Fabiano Silveira. Manifestouse oralmente pelo Conselho Federal da Ordem dos Advogados do Brasil o Secretário-Geral Cláudio Pereira de Souza Neto e, pelo Ministério Público Federal, o Subprocurador-Geral da República Eugenio Jose Guilherme de Aragão. 
Trata-se de procedimento de Comissão, encaminhado para estudo à Comissão Permanente de Eficiência Operacional e Gestão de Pessoas (CEOGP), originado da decisão proferida no Pedido de Providências (PP) $\mathrm{n}^{\mathrm{o}}$ 0002248-46.2012.2.00.0000, do relator para acórdão Conselheiro Ney José de Freitas, na 155a Sessão Ordinária, de 2/10/2012. No referido PP fora requerida a fixação de percentual para preenchimento de cargos, no Poder Judiciário, por negros e índios, incluindo o cargo de juiz substituto.

Na decisão emanada por este Conselho, entendeu-se fundamental, para a adoção de qualquer medida relacionada ao tema, a realização prévia de estudo aprofundado, nos seguintes termos:

Tal estudo, na minha ótica, é fundamental para a adoção de qualquer medida relacionada ao tema, "haja vista que não é possível estabelecer cotas como números mágicos. As proporções a serem observadas ou empregadas têm que se coadunar com as especificidades das composições raciais no Poder Judiciário nacional, bem assim com o tipo e a extensão das desigualdades, para que as medidas que venham a ser tomadas possam conter um planejamento adequado e uma execução que busque efetivamente o equilíbrio das disparidades verificadas". (ACOR16, fl. 14)

Assim, para subsidiar a deliberação do CNJ sobre eventual adoção de ações afirmativas, o Plenário decidiu encaminhar o supracitado procedimento à Comissão de Eficiência Operacional e Gestão de Pessoas (CEOGP) e à Comissão de Articulação Federativa e Parlamentar (Cafp) para realização de estudos e apresentação de proposta administrativa no prazo de 120 (cento e vinte) dias, verbis:

Por esses fundamentos, e diante do que decidiu a maioria do Plenário deste Conselho Nacional de Justiça, julgo procedente o pedido para o fim de encaminhar o presente procedimento à Comissão de Eficiência Operacional e Gestão de Pessoas e à Comissão de Articulação Federativa e Parlamentar, para que, após estudo, apresentem, no prazo de 120 (cento e vinte) dias, solução ao Plenário deste Conselho Nacional de Justiça sobre quais medidas administrativas possam ser tomadas no estabelecimento de diretrizes de políticas públicas voltadas ao Poder 
Judiciário, para o preenchimento de cargos de juízes substitutos e cargos, efetivos e em comissão, de servidores, destinando-se percentuais desses cargos a negros e índios (ACOR16, fl. 14).

Foram, então, autuados dois processos, um para cada comissão: 000675550.2012.2.00.0000, da Comissão de Articulação Federativa e Parlamentar (Cafp), e 0006940-88.2012.2.00.0000, da Comissão de Eficiência Operacional e Gestão de Pessoas (CEOGP), que foram apensados, tendo em vista o trabalho conjunto das duas Comissões (DESP18).

A Comissão de Eficiência Operacional e Gestão de Pessoas - CEOGP, em junho de 2012, constituiu um Grupo de estudos sobre o tema, formado pelo Departamento de Pesquisas Judiciárias (DPJ), Secretaria de Gestão de Pessoas (SSGP), Secretaria de Comunicação Social (SCS) e Departamento de Tecnologia da Informação (DTI), no âmbito do CNJ, e pela Secretaria de Políticas de Promoção da Igualdade Racial (Seppir), no âmbito da Presidência da República (INF3).

Constatada a inexistência de dados estatísticos ou informações suficientes ao estudo, o Grupo sugeriu a realização de um mapeamento étnico e socioeconômico do Poder Judiciário nacional. Assim, o DPJ apresentou um plano de ação para realização de coleta de (i) dados sobre magistrados e servidores do Poder Judiciário; (ii) dados sobre a oferta de mão de obra em condições de assumir cargos no Poder Judiciário; (iii) dados sobre candidatos de concursos para o Judiciário e (iv) informações nacionais e internacionais sobre ações afirmativas no serviço público civil (INF4).

Nesse sentido, a Seppir disponibilizou, para análise do DPJ, dados do Ministério da Educação (MEC) e do Instituto Nacional de Estudos e Pesquisas Educacionais Anísio Teixeira (Inep) sobre o perfil dos concluintes do curso de direito, de 2009 e 2010. A Coordenação Nacional do Exame da Ordem dos Advogados do Brasil (OAB), mediante solicitação da CEOGP, também disponibilizou informações étnicas dos candidatos dos Exames da Ordem VII e VIII (Eventos 12 a 15).

Quando do recebimento do processo de comissão, tendo em vista o prazo de 120 (cento e vinte) dias para realização do estudo, a CEOGP decidiu retomar o trabalho do grupo de estudo e priorizar a coleta de dados sobre magistrados e servidores, um "Censo do Poder Judiciário", por meio da aplicação de questionário simplificado a todos os magistrados e servidores, efetivos e comissionados, do Poder Judiciário (INF7). 
Na 19a Sessão Extraordinária do CNJ, o Conselho, por unanimidade, decidiu pela prorrogação do prazo de conclusão dos trabalhos por mais um ano (CERT24) e, em seguida, por mais seis meses para conclusão dos estudos.

O censo foi concluído. Foi a primeira pesquisa aberta a todos os servidores e magistrados brasileiros que visava traçar seu perfil e avaliar os níveis de satisfação em relação a dimensões da carreira, das condições de trabalho, da motivação para o trabalho, dentre outros. Um questionário eletrônico foi disponibilizado aos quase 17 mil juízes e aos mais de 285 mil servidores. Dentre esses, $64 \%$ dos magistrados e 60\% dos servidores de todos os 94 tribunais e conselhos responderam ao Censo.

O Censo apontou que a magistratura brasileira é composta por homens, brancos, com idade média de 45 anos, casados com pessoa de outro sexo e com filhos. 36\% da magistratura brasileira é composta por mulheres, com destaque para a justiça do trabalho com $47 \%$ de juízas. No universo pesquisado, há apenas 91 magistrados deficientes e apenas 36 que ingressaram nas vagas reservadas às pessoas com deficiência.

$14 \%$ dos magistrados declararam-se pardos, $1,4 \%$ pretos e $0,1 \%$ identificaram-se como indígenas. Nos últimos dois anos, o percentual de negros (pretos e pardos) que ingressaram na carreira cresceu de $15 \%$ para $19 \%$.

A nota técnica elaborada pelo Departamento de Pesquisas Judiciárias trouxe uma análise criteriosa dos dados colhidos pelo censo à luz da melhor literatura sobre o tema, o que nos auxilia e fundamenta a decisão plenária a ser proferida pelo CNJ.

É o relatório.

A legislação pertinente ao tema da não discriminação racial está presente no Estado brasileiro desde a Lei Afonso Arinos, Lei no 1.390 , de 3/7/1951, na qual se estipulava como contravenção a ação de colocar obstáculos a alguém para o acesso ao funcionalismo público e aos quadros das Forças Armadas em razão de preconceito de raça ou cor. Mas é apenas a partir dos anos 2000 que as políticas de ação afirmativa no Brasil passam a ser debatidas e colocadas em prática, especialmente em algumas Instituições de Ensino Superior públicas.

Como destacado no relatório do DPJ, em tese, as políticas de ações afirmativas poderiam ser implementadas considerando o PNAA - Programa Nacional de Ações Afirmativas instituído pelo Decreto Presidencial no 4.228, de 13/5/2002 - o qual já estabelecia uma política de cotas para mulheres, negros e deficientes na Administração Pública Federal direta e indireta no 
âmbito do Poder Executivo. Nesta normativa, os cargos com DAS (Direção e Assessoramento Superior), os contratados por empresas terceirizadas e os consultores contratados por meio de organismos internacionais são o alvo. Todavia, a regulamentação e o detalhamento deste Decreto jamais foram feitos, boa parte, em razão da falta de informações sobre raça/cor dos servidores públicos federais.

Alguns ministérios, então, como Ministério das Relações Exteriores, Ministério do Desenvolvimento Agrário, Ministério da Justiça, Ministério da Cultura passam a adotar percentuais para designação de servidores para cargos em comissão. Vale destacar, ainda, que de 2002 a 2012, há 43 municípios e quatro estados (Mato Grosso do Sul somou-se aos três estados anteriormente citados) que publicaram legislação para implementar uma política de reserva de vagas em concurso público para pessoas negras, conforme identificado em estudos citados pelo DPJ.

Recentemente, o PL no 6738/2013 foi aprovado pelo Congresso Nacional e promulgado pela Presidente da República no dia 9 de junho de 2014, dando origem à Lei no 12.990 , que já está em vigor e permanecerá vigente pelo prazo de 10 anos. Na lei, é estabelecido o percentual de 20\% de reserva de vagas para negros em concursos públicos para provimento de cargos efetivos e empregos públicos no âmbito da administração pública federal, das autarquias, das fundações públicas, das empresas públicas e das sociedades de economia mista controladas pela União. Ressalte-se que o artigo 5o da referida lei prevê seu monitoramento e avaliação anual pela Secretaria de Promoção de Políticas de Igualdade Racial - SEPPIR. ${ }^{1}$

No âmbito do sistema de Justiça, ainda há poucas iniciativas registradas como o concurso público para agente administrativo da Procuradoria-Geral de Justiça do Ministério Público do Rio Grande do Sul, que previu 16,13\% para reserva de vagas para pessoas pretas ou pardas, por meio do Edital no 091, publicado no dia 21 de março de 2013. No Paraná, com base na lei estadual no 14.274/2003, além da previsão de reserva de vagas para servidores do Poder Judiciário, houve publicação dos Editais nº 01/2009, noํㅜ 01/2011,

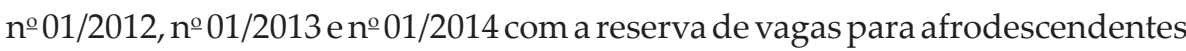
para o cargo de juiz substituto do Tribunal de Justiça daquele estado.

1 Art. 5ㅇ O órgão responsável pela política de promoção da igualdade étnica de que trata o $\S 1^{\circ}$ do art. 49 da Lei nº 12.288, de 20 de julho de 2010, será responsável pelo acompanhamento e avaliação anual do disposto nesta Lei, nos moldes previstos no art. 59 da Lei no 12.288 , de 20 de julho de 2010. 
Em março deste ano, o presidente do CNJ e do STF, assinou resolução que destina a candidatos negros $20 \%$ das vagas ofertadas para cargos efetivos no Conselho e na Suprema Corte em concursos públicos.

Esse é o cenário normativo da matéria. Com relação aos fundamentos teóricos da política de cotas, indico o parecer técnico do Departamento de Pesquisas Judiciárias anexo ao presente feito, que traz o suporte metodológico para a proposta normativa ora discutida. Passo ao exame, portanto, da pesquisa empírica que subsidia a ação a ser realizada pelo CNJ.

O Censo do Poder Judiciário alcançou uma taxa de respostas de $64 \%$ do universo total de 16.812 magistrados ativos e de $60 \%$ de um total de 285.328 de servidores ativos. A data de referência da pesquisa é 26 de agosto de 2013, momento do seu início, quando foram cadastrados os CPFs de todos os magistrados e servidores ativos até a referida data, permitindo que todos os cadastrados acessassem o questionário do Censo. Os resultados são bastante alvissareiros, tanto em termos da experiência internacional, quanto ao se ter em mente que se tratou da primeira pesquisa com tais objetivos feita no âmbito do Poder Judiciário.

Como evidenciado no parecer do DPJ, para "que seja possível estipular metas de inclusão de negros na força de trabalho do Judiciário, a principal informação necessária é o percentual de negros dentre aqueles que podem vir a assumir os cargos efetivos no âmbito do Poder Judiciário. Para alcançar tal percentual é imprescindível identificar quem possui os requisitos produtivos suficientes para cada tipo de cargo no Poder Judiciário. Tais metas de inclusão serão denominadas parâmetros de inclusão".

Os parâmetros de inclusão propostos pelo estudo de que nos valemos são diversos a depender do cargo e da Região de que tratamos. Há parâmetros para magistrados, cargos de servidores cujo requisito para ingresso é escolaridade de nível superior e cargos de servidores cujo requisito para ingresso é escolaridade de nível médio.

Segundo os dados técnicos, se adotada uma ação afirmativa nos certames para o cargo de magistrado, por exemplo, a presente proposta de cota deve levar em consideração a estatística de 22,5\% de negros em condições de adentrarem o Poder Judiciário na condição de magistrados, caso o parâmetro não seja regionalizado. Considerando-se um parâmetro regionalizado, a título exemplificativo, o Rio Grande do Sul deveria considerar o percentual de 5,1\%, enquanto a Bahia, 33,1\%. Para servidores com ensino superior, a porcentagem de negros é um pouco maior, de $25,0 \%$, e servidores de nível médio maior ainda - 39,8\%. Essas são as estimativas sobre o número de pessoas que 
potencialmente podem vir a competir pelos cargos oferecidos em concurso público no âmbito do Poder Judiciário.

De posse desse espelho da composição social, é preciso que se avalie o tempo necessário para que a vigência de ações afirmativas atinja os objetivos a que se propõe. A própria lei 12.990, de 9 de junho de 2014, que cuida do ingresso de negros nos cargos do serviço público civil em nível federal, fixou sua vigência em 10 anos.

Quanto a esse aspecto, mais uma vez, nos deparamos com diferenças entre cargos e ramos da Justiça. Quando aplicado um mesmo percentual de inclusão para todos os ramos de Justiça (critério que nos parece pragmaticamente mais adequado), a Justiça do Trabalho alcança primeiro (entre sete e oito anos) a meta de $22,2 \%$ de negros em seus quadros, enquanto os demais em não menos do que nove anos, considerada a cota de $10 \%$ (gráfico 2). Já na projeção que considera uma cota fixa em $20 \%$ de negros, à semelhança do modelo vigente no serviço público civil federal (Lei no 12.990), o comportamento dos ramos é parecido, muito embora o tempo seja bem menor, de quatro a cinco anos na Justiça do Trabalho e de cinco a seis nos dois outros ramos de Justiça considerados nestas projeções.

Não obstante as divergências reveladas pelo cuidadoso e fundamentado estudo elaborado pelo Departamento de Pesquisas Judiciárias, entendemos que o ideal, para estabelecermos uma política nacional de cotas que seja compreensível para todos e de simples aplicação, é a padronização dos percentuais. Por esse motivo, propomos a inclusão de uma avaliação, que seria feita por uma nova edição do censo do Poder Judiciário, após cinco anos de vigência da Resolução anexa. Assim, seria possível observar se alguns ramos da Justiça ou mesmo Regiões do Brasil tenham atingido as metas objetivadas pela ação afirmativa executada pelo Poder Judiciário.

Pelo exposto, voto pela aprovação da Resolução anexa.

RESOLUÇÃO de de de 2015.

Dispõe sobre a reserva aos negros, no âmbito do Poder Judiciário, de $20 \%$ (vinte por cento) das vagas oferecidas nos concursos públicos para provimento de cargos efetivos e de ingresso na magistratura. 
O PRESIDENTE DO CONSELHO NACIONAL DE JUSTIÇA, no uso de suas atribuições constitucionais e regimentais;

CONSIDERANDO o disposto na Lei no 12.990, de 9 de junho de 2014;

CONSIDERANDO o disposto no Estatuto da Igualdade Racial, Lei no 12.288 , de 20 de julho de 2010;

CONSIDERANDO o que foi decidido pelo Supremo Tribunal Federal na ADPF nํ 186/Distrito Federal;

CONSIDERANDO os resultados do Primeiro Censo do Poder Judiciário, realizado pelo Conselho Nacional de Justiça e;

CONSIDERANDO as deliberações do plenário do Conselho Nacional de Justiça nos autos do Pedido de Providências 0002248-46.2012.2.00.0000 e a decisão plenária do Conselho Nacional de Justiça nos autos do processo Comissão 0006940-88.2012.2.00.0000;

\section{RESOLVE:}

Art. 1ํㅡㄹ $\mathrm{A}$ reserva de vagas aos negros nos concursos públicos para provimentos de cargos efetivos nos órgãos do Poder Judiciário, inclusive de ingresso na magistratura, dar-se-á nos termos desta Resolução.

Art. 2 Serão reservadas aos negros o percentual mínimo de $20 \%$ (vinte por cento) das vagas oferecidas nos concursos públicos para provimento de cargos efetivos do Quadro de Pessoal dos órgãos do Poder Judiciário enumerados no art. 92, I-A, II, III, IV, V, VI e VII da Constituição Federal e de ingresso na magistratura dos órgãos enumerados no art. 92, III, IV, VI e VII.

$\S 1^{\circ} \mathrm{A}$ reserva de vagas de que trata o caput será aplicada sempre que o número de vagas oferecidas no concurso público for igual ou superior a 3 (três).

§2 Caso a aplicação do percentual estabelecido no caput resulte em número fracionado, este será elevado para o primeiro número inteiro subsequente, em caso de fração igual ou maior que 0,5 (cinco décimos), ou diminuído para o número inteiro imediatamente inferior, em caso de fração menor que 0,5 (cinco décimos).

Art. $3^{\circ}$ Os órgãos indicados no caput do art. $2^{\circ}$ poderão, além da reserva das vagas, instituir outros mecanismos de ação afirmativa com o objetivo de garantir o acesso de negros a cargos no Poder Judiciário, inclusive de ingresso na magistratura, bem como no preenchimento de cargos em comissão, funções comissionadas e vagas para estágio.

Art. 4 $\mathrm{A}$ reserva de vagas a candidatos negros constará expressamente dos editais dos concursos públicos dos órgãos do Poder Judiciário indicados no art. $2 \stackrel{\circ}{\circ}$. 
Parágrafo único. Os editais de que trata o caput deverão especificar o total de vagas correspondente à reserva para cada cargo oferecido.

Art. 5o Poderão concorrer às vagas reservadas a candidatos negros aqueles que se autodeclararem pretos ou pardos, no ato da inscrição no concurso público, conforme o quesito cor ou raça utilizado pela Fundação Instituto Brasileiro de Geografia e Estatística - IBGE.

§1ํㅗ A autodeclaração terá validade somente para o concurso público aberto, não podendo ser estendida a outros certames.

§2 Presumir-se-ão verdadeiras as informações prestadas pelo candidato no ato da inscrição do certame, sem prejuízo da apuração das responsabilidades administrativa, civil e penal na hipótese de constatação de declaração falsa.

§3ํ Comprovando-se falsa a declaração, o candidato será eliminado do concurso e, se houver sido nomeado, ficará sujeito à anulação da sua nomeação, após procedimento administrativo em que lhe sejam assegurados o contraditório e a ampla defesa, sem prejuízo de outras sanções cabíveis.

Art. $6^{\circ}$ Os candidatos negros concorrerão concomitantemente às vagas a eles reservadas e às vagas destinadas à ampla concorrência, de acordo com a sua classificação no concurso.

$\S 1^{\circ}$ Além das vagas de que trata o caput, os candidatos negros poderão optar por concorrer às vagas reservadas a pessoas com deficiência, se atenderem a essa condição, de acordo com a sua classificação no concurso.

$\S 2^{\circ}$ Os candidatos negros aprovados dentro do número de vagas oferecido para ampla concorrência não serão computados para efeito do preenchimento das vagas reservadas a candidatos negros.

§3을 Os candidatos negros aprovados para as vagas a eles destinadas e às reservadas às pessoas com deficiência, convocados concomitantemente para o provimento dos cargos, deverão manifestar opção por uma delas.

$\S 4^{\circ}$ Na hipótese de que trata o parágrafo anterior, caso os candidatos não se manifestem previamente, serão nomeados dentro das vagas destinadas aos negros.

§5을 $\mathrm{Na}$ hipótese de o candidato aprovado tanto na condição de negro quanto na de deficiente ser convocado primeiramente para o provimento de vaga destinada a candidato negro, ou optar por esta na hipótese do $§ 3^{\circ}$, fará jus aos mesmos direitos e benefícios assegurados ao servidor com deficiência.

Art. 7o Em caso de desistência de candidato negro aprovado em vaga reservada, a vaga será preenchida pelo candidato negro posteriormente classificado.

Parágrafo único. Na hipótese de não haver candidatos negros aprovados em número suficiente para que sejam ocupadas as vagas reservadas, as vagas 
remanescentes serão revertidas para a ampla concorrência e serão preenchidas pelos demais candidatos aprovados, observada a ordem de classificação no concurso.

Art. 8 A nomeação dos candidatos aprovados respeitará os critérios de alternância e de proporcionalidade, que consideram a relação entre o número total de vagas e o número de vagas reservadas a candidatos com deficiência e a candidatos negros.

Art. 9ำ Esta Resolução entra em vigor na data de sua publicação e vigorará até 9 de junho de 2024, término do prazo de vigência da Lei 12.990, de 9 de junho de 2014.

$\S 1^{\circ}$ Esta Resolução não se aplicará aos concursos cujos editais tiverem sido publicados antes de sua entrada em vigor.

$\S 2^{\circ}$ Em 5 (cinco) anos, contados da publicação desta Resolução, será promovida a segunda edição do censo do Poder Judiciário, oportunidade em que poderão ser revistos o percentual de vagas reservadas, bem como o prazo de vigência desta Resolução para cada ramo da Justiça, à luz dos dados coletados.

\title{
CONSELHO NACIONAL DE JUSTIÇA
}

210ª Sessão Ordinária

\section{PROCEDIMENTO DE COMPETÊNCIA DE COMISSÃO - 0006940- 88.2012.2.00.0000}

\author{
Relator: PAULO TEIXEIRA \\ Requerente: CONSELHO NACIONAL DE JUSTIÇA - CNJ \\ Requerido: CONSELHO NACIONAL DE JUSTIÇA - CNJ \\ Terceiros: $\quad$ Não definido
}

\section{CERTIDÃO DE JULGAMENTO}

CERTIFICO que o PLENÁRIO, ao apreciar o processo em epígrafe, em sessão realizada nesta data, proferiu a seguinte decisão:

Após o voto do Conselheiro vistor Fabiano Silveira, o Conselho, por unanimidade, aprovou a resolução nos termos propostos pelo Relator. Votou o Presidente. Presidiu o julgamento o Conselheiro Ricardo Lewandowski. Plenário, 9 de junho de 2015. 
Presentes à sessão os Excelentíssimos Senhores Conselheiros Ricardo Lewandowski, Nancy Andrighi, Ana Maria Duarte Amarante Brito, Flavio Sirangelo, Deborah Ciocci, Saulo Casali Bahia, Rubens Curado Silveira, Luiza Cristina Frischeisen, Gilberto Martins, Paulo Teixeira, Gisela Gondin Ramos, Emmanoel Campelo e Fabiano Silveira.

Manifestou-se oralmente pelo Conselho Federal da Ordem dos Advogados do Brasil, o Secretário-Geral Cláudio Pereira de Souza Neto e, pelo Ministério Público Federal, o Subprocurador-Geral da República Eugenio Jose Guilherme de Aragão.

Brasília, 9 de junho de 2015.

\section{CARLA FABIANE ABREU ARANHA}

Secretária Processual em exercício

Brasília, 2015-06-10.

Conselheiro Relator 